\title{
Methods of Motion Assessment of Upper Limb for Rehabilitation Application
}

\author{
Patrik Kutilek, Ana Carolina D'Angeles \\ Mendes de Brito, Jan Hejda, Eva Kutilkova, \\ Petr Volf, Barbora Adamova \\ Faculty of Biomedical Engineering \\ Czech Technical University in Prague \\ Kladno, Czech Republic \\ (kutilek, ana-carolina.dangeles-mendes-de-brit, \\ jan.hejda, eva.kutilkova, petr.volf, \\ adamobar)@fbmi.cvut.cz
}

\begin{abstract}
The aim of this paper is to describe methods proposed for motion capture subsystem of smart orthosis for quantitative evaluation of movement activity of upper limbs during a rehabilitation process carried out at a clinic or at home. To quantify the description of motion we used methods of evaluation of the relationship between measured variables and nonlinear methods. To test the functionality of the methods, we compared the movement of the dominant and nondominant limbs, assuming cyclical and acyclic movement, to obtain the expected values for a healthy population. In accordance with the goal, a group of cyclic and non-cyclic movements common to the home environment were proposed. The movements were divided according to the activities performed during sitting, standing and walking. It was: pen writing, typing on the keyboard / using the mouse, eating with a spoon and eating a croissant combing, lifting weights, reading a book, etc. Twenty healthy subjects participated in the study. Four gyro-accelerometers (Xsens Technologies B.V.) attached to the forearms and upper arms of both upper limbs were used to record the upper limb movements. The results show that the calculated values of dominant and non-dominant limb parameters differ significantly in most movements. The motion capture subsystem which uses the proposed methods can be used to evaluate the physical activity for quantification of the evaluation of the rehabilitation process, and thus, it finds use in practice.
\end{abstract}

Keywords: Motion assessment, Physical activity, Upper limb, Gyro-accelerometer

\section{INTRODUCTION}

Today, smart wearable orthosis of upper limb are not a common use for the evaluation of short-term and long-term movement activity. There are several projects, but there is no such thing as a detailed description of the motion capture subsystem of the orthosis and the data processing. Only preliminary designs were mentioned, [1],[2]. The methods for calculating the parameters for the assessment and evaluation of short-term and long-term movement activity in relation based on evaluation of the relationship between measured variables and nonlinear methods to the use in the orthosis have not been described.

\author{
Vojtech Havlas \\ Department of Orthopedics, 2nd Faculty of \\ Medicine \\ Motol University Hospital \\ Prague, Czech Republic \\ vojtech.havlas@fnmotol.cz
}

The aim of this article is to describe proposed methods based on evaluation of the relationship between measured variables and non-linear methods for evaluation of short-term and long-term physical activity by sensors suitable for use in the orthosis construction. Methods were tested and used to compare the movement of dominant and nondominant limbs, assuming cyclical and acyclical movement.

\section{METHODS AND MATERIALS}

The design of the methods to assess motion were based on the above-mentioned drawbacks. The method provides movement evaluation and was also carried out test of the evaluation of kinematic data of the movement of healthy subjects.

\section{A. Participants}

Twenty healthy subjects (age of 22.3 (SD 1.0) years), 8 women and 12 men, were recruited from the students at The Czech Technical University in Prague. The Edinburgh Handedness Inventory was used to assess the dominance of a person's right or left upper limb (e.g. [3]). In the study, there were three lefthanders and rest of the subjects was right-handers. The diagnostic evaluation included a detailed disease history, and an informed consent was obtained from each subject. The study was performed in accordance with the Helsinki Declaration. The study protocol was approved by the local Ethics Committee of the Faculty of Biomedical Engineering of the Czech Technical University (CTU) in Prague.

\section{B. Motion Capture Equipment}

In order to record the movement of upper limb segments is instrumental the use of sensors that will later be implemented into a smart orthosis. Inertial measurement units (IMU) offer a record of kinematic variables of angular and translational motion and was chosen for the construction of a smart orthosis. For this reason, the Xsens system (Xsens Technologies B.V.) with four gyro-accelerometer MTx sensors has been configured to measure body segment movements. The Xbus Master Motion capture system, which is a lightweight (330g) device, uses MTx units for the orientation and translation measurement of the 
Figure 1. Arrangement and application of the Xsens system with IMUs used to measure acceleration of upper limb segments.

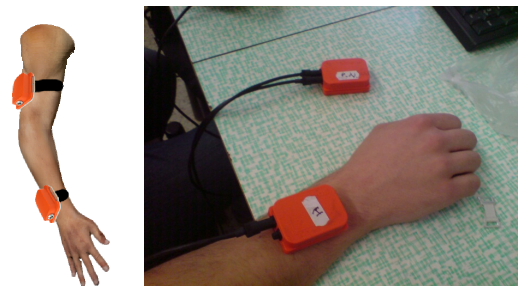

segments, [4]. The MTx unit with an embedded accelerometer and gyroscope represents an accurate IMU measurement of the drift-free 3-D orientation and 3-D acceleration, [5]. The data, i.e. the three Euler angles (roll $(\varphi)$, yaw $(\psi)$, pitch $(\theta)$ ) and three accelerations measured by each MTx unit are described in detail by [6], [7]. The MTx unit collected acceleration data at a sampling rate of $50 \mathrm{~Hz}$. Bias stability of the accelerometer is $0.02 \mathrm{~m} \cdot \mathrm{s}^{-2}$, orientation angular resolution of gyroscope is $0.05^{\circ}$, static accuracy is $0.5^{\circ}$, dynamic accuracy is $2^{\circ}$.

\section{Application of Sensors}

The Xsens motion sensors were placed in accordance with the recommendations of the Xsens manufacturer and similar studies, [8], [9]. The sensors were placed on body segments to record useful signals to assess the movement of the upper limbs. The exact placement of the sensors was as follows (see Fig. 1):

Sensor 1 - Right Upper Arm: point between the dorsal and lateral sides of the upper arm close to the caput lateral abdomen in the distal third of the forearm bone (at the site of the smallest deformation of the tissue during flexion in the elbow). The $\mathrm{X}$ axis of the sensor is parallel to the bone, its positive direction is oriented distally. The $\mathrm{Z}$ axis is in the positive direction in dorsolateral, the $\mathrm{Y}$ axis in the positive direction in ventrolateral, both are approximately $45^{\circ}$ laterally.

Sensor 2 - Right forearm: Dorsal forearm, $20 \mathrm{~mm}$ proximal to the center line of the radial and ulnar styloid. The sensor is oriented so that its Z-axis extends vertically from the dorsal surface of the forearm. Direction of the $\mathrm{X}$ axis parallel to the elbow bone, its positive direction is oriented distally. The positive direction of the $\mathrm{Y}$ axis is the same as the lateral direction.

Sensor 3 - Left Upper Arm: The specific point is determined as for sensor 1 .

Sensor 4 - Left forearm: The specific point is determined as for sensor 2 .

\section{Methods of Data Processing}

For the quantitative description of upper limb segment motion, parameters that by their value can characterize a certain motion property. Various methods are used to determine parameters. These methods can be further divided into:

- Methods of evaluation of time domain data, [10],
- Methods of evaluation of the relationship between measured variables [11],

- Non-linear methods of data [12].

Based on previous works and consultations with the Orthopedic and Traumatology Clinic, Hospital Motol, Charles University, we selected parameters according to the relationship between measured variables and non-linear methods.

For methods of analysis, common statistical characteristics such as $\max (\mathrm{v})$ or $\min (\mathrm{v})$ can be used, where $\mathrm{v}$ is the measured variable i.e. angle $(\alpha)$ or acceleration (a) in the $\mathrm{x}, \mathrm{y}$ or $\mathrm{z}$ directions of the sensor coordinate system. If we take into account more complex parameters implemented in custom made software, the first parameter will be based on range of measured variable $\triangle R A V r$, see [13]. For the calculation, we assume that the range of the measured variable in the time window is calculated by $R O V=\max (v)-\min (v)$. The $\triangle R A V r$ parameter is:

$$
\Delta R A V r=\frac{R A V r_{D}-R A V r_{N}}{R A V r_{D}},
$$

where:

$$
R A V r=\frac{R O V_{x}+R O V_{y}+R O V_{z}}{3},
$$

The $3 \mathrm{D}$ range of measured variable $(R A V)$ was calculated by the difference between the maximum and the minimum of variable measured by $3 \mathrm{D}$ gyroscope or $3 \mathrm{D}$ accelerometer. $\mathrm{D}$ indicates the $R A V \mathrm{r}$ for dominant limb and $N$ indicates the $R A V r$ for nondominant limb.

Second parameter used is the modified $\Delta \mathrm{Pr}$ parameter, [13]. $\triangle P r$ is based on the assumption that product of angular velocity and acceleration is related to power of movement [13]. Then the $\Delta P r$ is:

$$
\Delta P r=\frac{P r_{D}-P r_{N}}{P r_{D}},
$$

where

$$
\begin{aligned}
& \operatorname{Pr}=\left(R O V a_{x}+R O V a_{y}+R O V a_{z}\right), \\
& \cdot\left(R O V \alpha_{x}+R O V \alpha_{y}+R O V \alpha_{z}\right)
\end{aligned}
$$

$D$ indicates the $\operatorname{Pr}$ for dominant limb and $N$ indicates the $P r$ for non-dominant limb.

In the case of nonlinear methods, there are also a number of methods available for application. First, Largest Lyapunov exponent $\left(\lambda_{1}\right)$ was used in accordance with [14]:

$$
\lambda_{l}=\frac{1}{t_{k}-t_{0}} \cdot \sum_{i=1}^{k} \ln \frac{d_{i+1}}{d_{i}} .
$$

Where $d_{i}$ is the distance between the pair of nearest neighbors, i.e. data points in space, after $i$ discretetime steps, i.e. $i \cdot \Delta t$. Data points are defined by angular or acceleration values in specific directions of movement.

Sample entropy (SE) was also used in accordance with [15]: 


$$
S E=-\ln \frac{A}{B} .
$$

Where $A$ is the number of pairs of vector subsets of data of length $m+1$ which have a distance function less than $r$, while $B$ is the number of pairs of vector subsets of length $\mathrm{m}$ which similarly have a distance function less than $r$. For our experiments, the parameter $m=2$ was chosen and $r$ was set to be 0.2 times the standard deviation of the test data. Thus $B$ represents the probability that two sequences will match for $\mathrm{m}$ points and $A$ represents the probability that two sequences will match for $m+1$ points across all possible comparisons. A full and detailed description of the $S E$ calculation is described in detail in [16], [17].

We also used the Hurst exponent $(H)$ calculated in accordance with [18], [19]:

$$
H=\frac{\log \left(\frac{R}{S}\right)}{\log (k)} .
$$

Where

$$
\begin{aligned}
& S=\sqrt{\frac{1}{k} \cdot \sum_{i=l}^{k}\left(v_{i}-\frac{1}{k} \cdot \sum_{i=1}^{k} v_{k}\right)^{2}}, \\
& R=\max \left(\sum_{i=1}^{k}\left(v_{i}-\frac{1}{k} \cdot \sum_{i=1}^{k} v_{k}\right)\right), \\
& -\min \left(\sum_{i=1}^{k}\left(v_{i}-\frac{1}{k} \cdot \sum_{i=1}^{k} v_{k}\right)\right)
\end{aligned}
$$

i.e. $H$ is obtained from the double-log graph by a least square fit.

\section{E. Test procedure}

A group of cyclical and non-cyclical movements common to the home environment were proposed. The division of movements was according to the activity of during sitting, standing and walking. The list of selected activities is shown in Table 1.The motion sensor was placed on the subject prior to measurement in accordance with the description above. Each subject was instructed to perform a sequence of activities at the Table 1. During the movements the motion data were recorded. After performing all of the movement activities, the data for each activity was processed separately to compare activities

After calculating the values for the individual movement activities of each subject, the statistical analysis was performed with the use of MatLab sw. The movement of the dominant and non-dominant limb was compared. The Jarque-Bera test was used to test the normal distribution of all parameters (significance level was 5\%). The Wilcoxon Test was used to assess the significance of the differences between dominant and non-dominant limbs. The significance level was set at was $5 \%$.

\section{RESULTS}

The Jarque-Bera test in some cases did not confirm the hypothesis of normal distribution of data, thus, the Wilcoxon test was used for analysis. Using the Wilcox test, the parameters for the dominant and nondominant limb was compared. Table 2 shows an overview of differences in result with statistically significant differences, i.e. $\mathrm{p}<0.05$.

TABLE I. CYCLICAL AND NON-CYCLICAL MOVEMENTS USED TO TEST METHODS OF DATA PROCESSING.

\begin{tabular}{|c|c|c|c|c|}
\hline Method & Activity & Variable & Segment & Parameter \\
\hline \multirow{12}{*}{ Sitting } & \multirow{2}{*}{$\begin{array}{l}\text { writing } \\
\text { with a pen }\end{array}$} & angle & forearm & $\Delta \mathrm{RAVr}$ \\
\hline & & acceleration & forearm & $\Delta \mathrm{Pr}$ \\
\hline & \multirow{3}{*}{$\begin{array}{l}\text { typing on } \\
\text { the } \\
\text { keyboard / } \\
\text { using the } \\
\text { mouse }\end{array}$} & \multirow{2}{*}{ angle } & $\begin{array}{l}\text { upper } \\
\text { arm }\end{array}$ & $\mathrm{H}, \triangle \mathrm{RAVr}$ \\
\hline & & & forearm & $\Delta \mathrm{RAVr}, \lambda_{1}$ \\
\hline & & acceleration & forearm & $\Delta \mathrm{Pr}$ \\
\hline & $\begin{array}{l}\text { eating } \\
\text { with a } \\
\text { cutlery }\end{array}$ & angle & forearm & $\triangle \mathrm{RAVr}$ \\
\hline & \multirow{3}{*}{$\begin{array}{l}\text { lifting } \\
\text { weight } \\
\text { held in } \\
\text { one hand }\end{array}$} & \multirow{2}{*}{ angle } & $\begin{array}{l}\text { upper } \\
\text { arm }\end{array}$ & $\lambda_{1}$ \\
\hline & & & forearm & $\Delta \mathrm{RAVr}$ \\
\hline & & acceleration & forearm & $\lambda_{1}$ \\
\hline & \multirow{3}{*}{ combing } & angle & $\begin{array}{l}\text { upper } \\
\text { arm }\end{array}$ & $\Delta \mathrm{RAVr}$ \\
\hline & & \multirow{2}{*}{ acceleration } & $\begin{array}{l}\text { upper } \\
\text { arm }\end{array}$ & $\lambda_{1}$ \\
\hline & & & forearm & $\Delta \mathrm{Pr}$ \\
\hline \multirow{6}{*}{ Standing } & \multirow{2}{*}{$\begin{array}{l}\text { waving at } \\
\text { head level }\end{array}$} & angle & forearm & $\begin{array}{l}\mathrm{H}, \Delta \mathrm{RAVr}, \\
\lambda_{1}\end{array}$ \\
\hline & & acceleration & $\begin{array}{l}\text { upper } \\
\text { arm }\end{array}$ & $\lambda_{1}$ \\
\hline & combing & angle & forearm & $\mathrm{H}$ \\
\hline & $\begin{array}{l}\text { tooth } \\
\text { brushing }\end{array}$ & angle & forearm & $\mathrm{H}$ \\
\hline & \multirow{2}{*}{$\begin{array}{l}\text { lifting } \\
\text { weight }\end{array}$} & \multirow{2}{*}{ angle } & $\begin{array}{l}\text { upper } \\
\text { arm }\end{array}$ & $\mathrm{H}$ \\
\hline & & & forearm & $\Delta \mathrm{RAVr}$ \\
\hline \multirow{6}{*}{ Walking } & \multirow{3}{*}{$\begin{array}{l}\text { waving at } \\
\text { head level }\end{array}$} & \multirow{2}{*}{ angle } & $\begin{array}{l}\text { upper } \\
\text { arm }\end{array}$ & $\Delta \mathrm{RAVr}$ \\
\hline & & & forearm & $\mathrm{H}$ \\
\hline & & acceleration & $\begin{array}{l}\text { upper } \\
\text { arm }\end{array}$ & $\Delta \mathrm{Pr}$ \\
\hline & $\begin{array}{l}\text { lifting the } \\
\text { weight } \\
\text { held in } \\
\text { one hand } \\
\text { in the } \\
\text { middle of } \\
\text { the path }\end{array}$ & angle & forearm & $\mathrm{H}, \Delta \mathrm{RAVr}$ \\
\hline & $\begin{array}{l}\text { throw a } \\
\text { ball in the }\end{array}$ & angle & $\begin{array}{l}\text { upper } \\
\text { arm }\end{array}$ & $\Delta \mathrm{RAVr}$ \\
\hline & $\begin{array}{l}\text { middle of } \\
\text { the path } \\
\text { trasy }\end{array}$ & acceleration & $\begin{array}{l}\text { upper } \\
\text { arm }\end{array}$ & $\Delta \mathrm{Pr}$ \\
\hline
\end{tabular}

\begin{tabular}{|l|l|}
\hline Method & \multicolumn{1}{|c|}{ Activity } \\
\hline Sitting & $\begin{array}{l}\text { writing with a pen; typing on the keyboard / using the } \\
\text { mouse; eating with a cutlery; waving at head level; } \\
\text { combing; lifting weight. }\end{array}$ \\
\hline Standing & $\begin{array}{l}\text { waving at head level; combing; tooth brushing; lifting } \\
\text { weight; reading a book. }\end{array}$ \\
\hline Walking & $\begin{array}{l}\text { slow walking; running; waving at head level; lifting the } \\
\text { weight in the middle of the path; throw a ball in the } \\
\text { middle of the path. }\end{array}$ \\
\hline
\end{tabular}

TABLE II. OVERVIEW OF IDENTIFIED STATISTICALLY SIGNIFICANT DIFFERENCES IN PARAMETERS WHEN COMPARING DOMINANT AND NON-DOMINANT ARM. 


\section{DISCUSSION}

For asynchronous movements, it is assumed that a significant difference will be found for paired segments, i.e. combing when the subject uses only one hand. The tests confirmed this assumption in most cases. None of the quantitative methods showed a statistically significant difference in purely cyclical movements, such as walking without additional movement. In some cases, however, only individual methods have been successful in identifying differences. Only exceptionally more methods led to the same conclusion. Basically, these were only cases with the most significant differences in arm movements, such as waving with one arm. This is the case when the measured specific kinematic variables differ very significantly, i.e. angles during waving with one arm.

The aim of this work was to present the methods of measurement for the identification of movement on determined activities. It was used 4 gyroaccelerometers placed at the upper limbs. It is not evident from the results what methods (based on evaluation of the relationship between measured variables or non-linear) are more appropriate. We can say that the most successful in identifying differences in movements are: $H, \Delta R A V r, \lambda_{1}$. On the contrary, it turns out that Sample entropy has not identified any difference and is inappropriate for our application.

Because not all methods lead to the same conclusions, for future application and research it will be appropriate to perform further tests, for what types and ranges of the movements, and especially the duration of the movements, the methods are most appropriate. Based on the above, either a smaller number of methods will be used to determine the specific type of movement, or a system for aggregation of the results of the calculations by the methods and estimating a particular physical activity based on multiple parameters will be proposed. There are limitations to our study. The most important one is that the sample of the subjects was small and probably not representative of the larger population. However, to test the basic attributes of the method proposed for the study of operational preparedness in this preliminary study, a sample of subjects is sufficient.

\section{CONCLUSION}

In this work were described methods proposed for evaluation and identification of physical activity. The main benefit of this work is the selection of motion capture sensors and methods to be used for the upper limb monitoring in order to evaluate the movement of arm. According to the requirements of the clinical practice, the sensors and methods selected were able to acquire information to evaluate the upper-limbs movements of determined daily life activities and compare the behavior of the dominant and nondominant limb. The method here proposed can be used in future construction of orthosis for the upper-limbs to evaluate and move the body of a patient.

\section{REFERENCES}

[1] D. P Romilly, C Anglin, R. G Gosine, C Hershler, S. U. Raschke, "A Functional Task Analysis and Motion
Simulation for the Development of a Powered Upper-Limb Orthosis", IEEE Transactions on Rehabilitation Engineering, pp 119-129, 1994.

[2] R. Rupp, M. Rohm, M. Schneiders, A. Kreilinger, G. R Müller-Putz, "Functional rehabilitation of the paralyzed upper extremity after spinal cord injury by noninvasive hybrid neuroprostheses", Proceedings of the IEEE, pp 954-968, 2015.

[3] R. C. Oldfield, "The assessment and analysis of handedness", The Edinburgh inventory. Neuropsychologia, pp 97-113, 1971

[4] P. Kutilek, O. Cakrt, J. Hejda, R.Cerny, "Com-parative measurement of the head orientation using camera system and gyroscope system", 13th Mediterranean conference on medical and biological engineering and computing, Seville, Spain, IFMBE Proceedings, Volume 41, pp 1519-1522, 2013

[5] P. Kutilek, V. Socha, O. Cakrt, J. Schlenker, L. Bizovska, "Trajectory length of pitch vs. roll. Technique for assessment of postural stability" Acta Gymnica, pp 85-92, 2015

[6] J. H Allum, L. B. O.Nijhuis, M. G. Carpenter: Differences in coding provided by proprioceptive and vestibular sensory signals may con-tribute to lateral instability in vestibular loss subjects. Experimental brain research, 184(3), 391-410, 2008

[7] Á. Gil-Agudo, L. A. Reyes-Guzman, Dimbwadyo-Terrer, I. Peñasco-Martín, B. Bernal-Sahún, A. P.López-Monteagudo, A. Ama-Espinosa, J. L Pons: A novel motion tracking system for evaluation of functional rehabilitation of the upper limbs. Neural regeneration research, 8(19), p. 1773-1782, 2013

[8] D. Stirling, A. Hesami, C. Ritz, K. Kdistambha, F. Naghdy: Symbolic Modelling of Dynamic Human Motions. Biosensors. Pier Andrea Serra (Ed.), InTech, DOI: 10.5772/7215, 2013

[9] F. Lorussi, N. Carbonaro, D. D. Rossi, A. Tognetti, “A biarticular model for scapular-humeral rhythm reconstruction through data from wearable sensors", J Neuroeng Rehabil. 13, pp 40, 2016

[10] D. Winter, "Stiffness Control of Balance in Quiet Standing", Journal of Neurophysiology, pp. 1211-1221, 1998

[11] P. Kutilek, B. Farkasova, "Prediction of Lower Extremities' Motion by Angle-angle Diagrams and Neural Networks", Acta of Bioengineering and Biomechanics, pp 57-65, 2011

[12] S. M. Bruijn, "Assessing Stability of Human Locomotion: a review of current measures", Journal of the Royal Society Interface, 2013

[13] B. Coley, B. M. Jolles, A. Farron, A. Bourgeois, F. Nussbaumer, C. Pichonnaz, K. Aminian, "Outcome evaluation in shoulder surgery using 3D kinematics sensors", Gait \& Posture, Vol 25, pp 523-532, 2007

[14] A. Wolf, J. B. Swift, H. L. Swinney, J. A. Vastano, "Determining Lyapunov exponents from a time series", Physica 16D, pp 285-317, 1985

[15] D. E. Lake, J. S. Richman, M. P. Griffin, J. R. Moorman, "Sample entropy analysis of neona-tal heart rate variability", American Journal of Physiology - Regulatory, Integrative and Comparative Physiology, Vol. 283 no. 3, 2002

[16] M. O. Sokunbi, "Sample entropy reveals high discriminative power between young and elderly adults in short fMRI data sets", Front. Neuroinform., 2014

[17] B. Singh, M. Singh, V. K. Banga, "Sample Entropy based HRV: Effect of ECG Sampling Frequency", Biomedical Science and Engineering, 2014

[18] Z. Jian-Jun, N. Xin-Bao, Y. Xiao-Dong, H. Feng-Zhen, H. Cheng-Yu, "Decrease in Hurst expo-nent of human gait with aging and neurodegenerative diseases", Chin. Phys. Soc. and IOP Publishing Ltd, Chinese Physics B, Vol 17, 2008

[19] A. Goshvarpour, A. Goshvarpour, "Nonlinear Analysis of Human Gait Signals", International Journal of Information Engineering and Electronic Business(IJIEEB), Vol.4, pp 1521,2012 